\title{
Ultrasound-Assisted and Microwave-Assisted Extraction, GC-MS Characterization and Antimicrobial Potential of Freeze-dried L. camara Flower
}

\author{
N.A. Nanje Gowda* (D), Chennappa Gurikar $(\mathbb{D})$, M.B. Anusha $(\mathbb{D}$ and \\ Soumya Gupta
}

Department of Food Technology, Faculty of Life and Allied Health Sciences, Ramaiah University of Applied Sciences, Bengaluru - 560 054, Karnataka, India.

\begin{abstract}
Lantana camara is known to have anti-bacterial properties which can be exploited to develop a natural food preservative. There is huge demand for natural preservatives in food industry due to the increased health risks associated with synthetic preservatives, development of efficient extraction methods are essential to retain heat sensitive bioactive compounds. The aim of this study was to compare the performance of microwave-assisted extraction (MAE), ultrasound-assisted extraction (UAE), and conventional solvent extraction (CSE) methods for extraction of freeze-dried lantana flower. The phytochemicals in freeze-dried flowers were characterized by GC-MS analysis and antibacterial properties were tested at different concentrations $(50,100$, and $150 \mu l)$ against E.coli, Salmonella, and $S$. aureus. It was evident that the UAE offered the highest yield (64\%), followed by MAE (53\%) and CSE (49\%) with distilled water as solvent. The freeze-dried extract possessed a high amount of tannins $(417 \mu \mathrm{g} / \mathrm{g})$, followed by flavonoids such as catechol $(88 \mu \mathrm{g} / \mathrm{g})$ and quercetin $(9.2 \mu \mathrm{g} / \mathrm{g})$. The antibacterial potential results revealed that only distilled water-based extraction techniques offered positive inhibition zones of 2.0-2.67 mm (MAE), 1.67-2.67 $\mathrm{mm}$ (UAE), and 1.67-2.17 mm (CSE) against all three organisms, while the chloroform based extracts had no inhibition effect. The microwave-assisted extract at $150 \mu \mathrm{l}$ concentration offered a significant inhibitory effect against all three pathogens. The GC-MS profiling of bioactive compounds in flower extract revealed the presence of hexadecanoic acid as the major phytochemical compound in all three extraction techniques. The study revealed that the chloroform extract failed to exhibit an antibacterial effect due to the absence of alkaloids, saponins, and anthraquinones as a result of its neutralizing effect.
\end{abstract}

Keywords: Lantana camara, extraction, antimicrobial, freeze-dried, ultrasound-assisted, microwave-assisted

*Correspondence: nanjegowdana@gmail.com

(Received: December 4, 2021; accepted: January 4, 2022)

Citation: Gowda NAN, Gurikar C, Anusha MB, Gupta S. Ultrasound-Assisted and Microwave-Assisted Extraction, GC-MS Characterization, and Antimicrobial Potential of Freeze-dried L. camara Flower. J Pure Appl Microbiol. 2022;16(1):526-539. doi: 10.22207/JPAM.16.1.50

(C) The Author(s) 2022. Open Access. This article is distributed under the terms of the Creative Commons Attribution 4.0 International License which permits unrestricted use, sharing, distribution, and reproduction in any medium, provided you give appropriate credit to the original author(s) and the source, provide a link to the Creative Commons license, and indicate if changes were made. 


\section{INTRODUCTION}

L. camara is a therapeutic aromatic plant that grows across the world as a notorious weed species as well as an ornamental shrub, commonly known as wild savage or red sage. ${ }^{1}$ It is a local weed plant species of tropical and subtropical areas of America, Asia, and Africa and about 150 species have been recorded. ${ }^{2}$ The hybridization of this species is widespread, the shape of inflorescence changes with age, and flower color varies with maturity. ${ }^{3,4}$ Lantana has been used as a traditional medicinal herb for over a hundred years for treating chickenpox, measles, tetanus, rheumatism, malaria, high blood pressure, eczema, tumors, and swellings, etc. ${ }^{5}$ Several bioactive compounds such as alkaloids, terpenoids, flavonoids, steroids, phenolics, glycosides are present as major phytoconstituents. ${ }^{2}$ Lantana roots are the putative source of oleanolic acid and flowers contain a higher amount of total phenols followed by the tannins and flavonoids. ${ }^{1,2}$ Lantana comprises some important bioactive compounds include quercetin, triterpenoids, flavonoids, steroids, oleanolic acid, isorhamnetin lantadene $A, \beta$ - sitosterol pomonic acid, verbacosides, coumaric acid, lanatoside, octadecanoic acid, naphthoquinones. palmitic acid, and docosanoic acid. ${ }^{6}$ The Lantana possess a wide range of biological activities such as anti-inflammatory, antibacterial, antioxidant, insecticidal, allelopathic, and larvicidal. ${ }^{2}$ Owing to its abundant availability, the industrial applications of Lantana plant parts oil are being extensively researched across the globe.

On the other hand, food poisoning and spoilage-causing microbes are the major concern in the food industry. Artificial preservatives are extensively used to prevent the growth of foodborne pathogens and increase the shelf life of food products. Generally, synthetic preservatives like sodium benzoate, butylated hydroxyl-toluene, and butylated hydroxyl-anisole are used which are known to cause adverse health effects. ${ }^{1}$ These artificial preservatives are known to cause allergic reactions, toxicity, and life-threatening side effects on consumers in the long run. ${ }^{7}$ On other hand, various plant extracts enriched with phenolic components are found to possess a potential antimicrobial activity. Therefore, the usage of phytochemical compounds from plant extracts as a natural preservative and in pharmaceutical has gained tremendous interest in recent years against harmful synthetic preservatives. . $^{1,8,9}$ Thus, the adverse effects of synthetic preservatives could be addressed by developing novel plantbased potentially effective, and safer natural preservatives.

The extraction methods and solvents affect the functional properties of the extract. Several extraction methods for bioactive compounds include solvent based, percolation, ultrasound-assisted, microwave-assisted, microwave-hydrodistillation and supercritical fluid based, enzyme-assisted, solvent-free microwave and have been applied for maximum recovery of essential oils from plant matrices. ${ }^{10-18}$ Among them, the conventional methods (solvent extraction or leaching or hydro distillation) involve long processing time and low efficiency due to the degradation of active compounds. ${ }^{13,16,18}$ The pre-extraction and extraction procedures also play a vital role in the processing of the bioactive constituents from plant materials. ${ }^{19}$ Food industries are looking for new extraction techniques due to the safety concern, environmental restrictions, minimize waste and energy. ${ }^{16,17}$ Significant advances have occurred in the extraction of phytochemicals from medicinal plants using modern extraction methods. Among several, the microwave-assisted (MAE) and ultrasoundassisted extraction (UAE) methods proved to be the most efficient techniques at cheaper cost, higher purity and shorter processing time compared to conventional solvent extraction. ${ }^{16,19,20}$ Consequently, elucidating the most productive extraction technique for lantana and its effect on the antimicrobial property is a significant challenge and an unexplored area with respect to food industry application. ${ }^{21}$ Till date, there were no studies on extraction of freeze dried lantana flower using MAE and UAE techniques and the effect of its parameters on the oil yield, antimicrobial properties and bioactive compounds. Therefore, the aim of this study was to understand the effect of extraction techniques and solvents on the extract yield of freeze-dried Lantana flowers and their antimicrobial potential at different concentrations. The characterization of bio-active compounds in the freeze-dried Lantana flower was also performed using GM-MS analysis. 


\section{MATERIALS AND METHODS Sample preparation}

Fully bloomed L. camara flowers were harvested near Nagenahalli Village $\left(13^{\circ} \mathrm{N}, 77^{\circ} \mathrm{E}\right)$, Bangalore, India during December 2020. The healthy and fresh flowers were hand separated from the stalk, washed, and freeze-dried. The sample was pre-frozen at $-40^{\circ} \mathrm{C}$ in a deep freezer (Brand: Thermo Fisher, Model: PL6500) and freezedried using a freeze dryer (Brand: BIOLAB. BFBT103-A). The freeze-dried sample was then coarse ground and sieved using a sieve size of $2 \mathrm{~mm}$ in diameter. The ground sample was then stored in air-tight dark bottles under refrigerated conditions $\left(4^{\circ} \mathrm{C}\right)$ for further use.

\section{Extraction procedures \\ Conventional solvent extraction (CSE)}

Several studies have been conducted for extracting the bioactive components using petroleum ether, ethanol and methanol, but the chloroform and aqueous extract have been reported to exhibit high anti-microbial property due to this chloroform was selected as major solvent in this study. ${ }^{22-25}$ About 5 grams of freeze-dried powdered sample was used in each extraction experiment using Chloroform (B.P $<61.2^{\circ} \mathrm{C}$ ) and Distilled water (B.P $<100^{\circ} \mathrm{C}$ ) as solvents. The conventional solvent extraction (CSE) was carried out at the boiling point of solvents in a soxhlet apparatus for 24 to $48 \mathrm{~h}$. The extract was then filtered through Whatman No. 1 filter paper and concentrated using a rotary evaporator (Brand: HAHN SHIN. HS-2005V-N) at temperature below the boiling point of solvents. The yield (\%) was calculated using the equation reported earlier. ${ }^{17,26}$ The dry extracts were dissolved in the respective solvent and stored at $4^{\circ} \mathrm{C}$ in a refrigerator for further studies. ${ }^{6}$

\section{Ultrasound-assisted extraction (UAE)}

The flower samples extraction was performed using an ultrasonic probe sonicator (Brand: LABMAN. PRO-650, $20 \mathrm{kHz}, 0-650 \mathrm{~W}$ ) with a provision to adjust the required power and time. About $1 \mathrm{~g}$ of sample with $50 \mathrm{ml}$ of solvent was taken in a $100 \mathrm{ml}$ beaker and covered with aluminum foil to prevent loss of solvent due to evaporation. The samples were sonicated at $400 \mathrm{~W}$ at $20 \mathrm{kHz}$, for $15 \mathrm{~min}$ at a constant temperature of $45 \pm 2^{\circ} \mathrm{C}$. The extract was then filtered, concentrated under vacuum, dissolved in a few $\mathrm{ml}$ of the respective solvent, and stored at low temperature $\left(4^{\circ} \mathrm{C}\right)$ for further studies. ${ }^{27,28}$

Microwave-assisted extraction (MAE)

MAE method has a great potential to extract essential oils from plant materials. ${ }^{16}$ A microwave synthesizer (Brand: RAGAtech. RG-31L, $750 \mathrm{~W}$ ) was used for the microwave treatment. About $3 g$ of sample was mixed with 200 $\mathrm{ml}$ of solvent in a conical flask and microwaved at $700 \mathrm{~W}$ for $5 \mathrm{~min}$ with an intermittent break time of $2 \mathrm{~min}$. A pre-leaching time of $10 \mathrm{~min}$ was given to each suspension before microwave irradiation. The microwave irradiation was done in an intermittent way i.e., irradiation-cooling-irradiation with a time duration of $5 \mathrm{~min}$ for irradiation and $2 \mathrm{~min}$ for cooling. After treating the sample in a microwave at $700 \mathrm{~W}$ for $5 \mathrm{~min}$, the extraction was carried out. The other processes like filtration, concentration and storage were done similarly to that of the conventional solvent extraction method. ${ }^{29}$

Determination of phytochemicals in a flower extract

The major phytochemicals such as total phenols, tannins, and flavonoids, etc. in the flower extract were analyzed using standard protocols. The phenolic content and flavonoid content were determined by following colorimetric assay and tannin content was determined using FolinsCiocalteu assay. ${ }^{30}$

\section{Culture media \& preparation}

MRS (De Man, Rogosa, and Sharpe) and EMB (Eosin Methylene Blue) agar was used for sub-culturing the microbial strains. Muller Hinton Agar media was used throughout the study. In the present study, the antimicrobial properties of Lantana flower extract were evaluated against S. aureus, E.coli, and Salmonella. The lyophilized powder of these strains was added to the sterile nutrient broth to incubate at $37^{\circ} \mathrm{C}$ for 2 days and sub-cultured in an appropriate media. ${ }^{5}$

\section{Determination of the antibacterial activity of} flower extract

The antimicrobial activities of Lantana camara flower extracts obtained from different extraction methods (CSE, MAE \& UAE) using two solvents (chloroform and distilled water) were evaluated by the agar well diffusion method. ${ }^{31}$ An appropriate media for the growth of test organisms were poured in a petri plate and allowed to set. Into the prepared bacterial suspension, a 
sterile cotton swab was dipped and streaked over the entire surface of the plates to form a bacterial lawn. Four wells were punched on the plates using a sterile cork borer, and dispensed with the flower sample extracted by conventional solvent extraction method, three wells with the extract and the fourth one with control (solvent alone). This procedure was repeated for extracts obtained from microwaved and ultrasound-treated samples. Then the plates were incubated for 24 to 48 hours at $37^{\circ} \mathrm{C}$. After incubation, the diameter of the zone of inhibition $(\mathrm{mm})$ was measured to determine the antibacterial activity of the bioactive compounds. ${ }^{31}$ GC-MS analysis of bioactive compounds

GC-MS analysis of the active chloroform extract of L. camara was carried out by using the GC-MS/MS instrument (Model: QP2010 Plus, Shimadzu, Japan). The identification of the phytochemicals in the sample was carried out using a QP2010 gas chromatography with Thermal Desorption System, (TD 20) coupled with mass spectroscopy. The ionization voltage was $70 \mathrm{eV}$. Gas Chromatography was conducted in the temperature programming mode with a Restek column ( $0.25 \mathrm{~mm}, 60 \mathrm{~m}, \mathrm{XTI}-5)$. The initial column temperature was $60^{\circ} \mathrm{C}$ for $1 \mathrm{~min}$, and then increased linearly at $70^{\circ} \mathrm{C} \mathrm{min}^{-1}$ to $220^{\circ} \mathrm{C}$, held for $2 \mathrm{~min}$, followed by linear temperature increase at $10^{\circ} \mathrm{C} \mathrm{min}^{-1}$ to $280^{\circ} \mathrm{C}$ for $10 \mathrm{~min}$. The temperature of the injection port was $280^{\circ} \mathrm{C}$ and the GC-MS interface was maintained at $280^{\circ} \mathrm{C}$. The sample was introduced via an all-glass injector working in the split mode, with a helium ( $99.9 \%$ purity) carrier gas flow rate of $1.2 \mathrm{~mL} \cdot \mathrm{min}^{-1}$. The identification of compounds was accomplished by comparison of retention time, peak area percentage, and fragmentation pattern, as well as with mass spectra of the GC-MS. ${ }^{32}$ The identification of compounds from the spectral data was based on the available mass spectral records (NIST.17 and WILEY libraries).

\section{Statistical analysis}

The effect of pre-treatments, solvents on extract yield, the effect of flower extract concentration on antibacterial activities, and the statistical analysis (with a probability value of $p \leq 0.001$ considered to be statistically significant) was done with Response surface methodology (RSM) called I-Optimal Design by using Design Expert Statistical Software (ver. 11.1.2.0).

\section{RESULTS AND DISCUSSION \\ Effect of solvents and extraction techniques on extract yield of lantana flowers \\ The flower extract yield obtained for} different extraction techniques and solvents is presented in Table 1. Among three extraction techniques and two solvents, the distilled water as a solvent with ultrasound-assisted extraction (UAE) offered a significantly $(P<0.001)$ higher yield $(64 \%)$, followed by microwave-assisted extraction (53\%) and conventional solvent extraction (CSE) (49\%). The distilled water as solvent offered a significantly $(P<0.001)$ higher extraction yield than chloroform. This was due to the difference in polar nature of aqueous solvents such as water and also due to the fact that phenolics are often extracted better in polar solvents than non-polar solvents 27,33,34 $^{27}$. extract yield depends on the nature of the solvent, components, target material, and assimilation during extraction. ${ }^{6,10}$ The improvement of yield in UAE technique could be attributed to cavitation and thermal effects of the ultrasound radiation, which causes effective cell wall disruption, facilitating solvent access to the cell contents and enhanced mass transfer. ${ }^{10,11,13,35,36}$ The $4 \%$ increase

Table 1. L. camara flower extract yield as affected by extraction technique and solvents

\begin{tabular}{lccc}
\hline No. & Solvents & Extraction techniques & Extract Yield (\%) \\
\hline 1. & Distilled water & Conventional solvent extraction (CSE) & $49.22 \pm 1.10$ \\
2. & Chloroform & Conventional solvent extraction (CSE) & $5.78 \pm 0.79$ \\
3. & Distilled water & Ultrasound-assisted extraction (UAE) & $64 \pm 1.41$ \\
4. & Chloroform & Ultrasound-assisted extraction (UAE) & $4.2 \pm 0.70$ \\
5. & Distilled water & Microwave-assisted extraction (MAE) & $53 \pm 2.82$ \\
6. & Chloroform & Microwave-assisted extraction (MAE) & $4.11 \pm 1.15$ \\
\hline
\end{tabular}

Note: each value is expressed as mean \pm standard deviation (SD) $(n=3)$. 
in yield in the MAE technique compared to conventional solvent extraction (CSE), was due to the rapid volumetric heating of cells which disrupts the weak hydrogen bonds generated by the dipole

Table 2. Total phenols, flavonoids, and tannins in lantana flower extracts

\begin{tabular}{lc}
\hline Phenolic content & Values $(\mu \mathrm{g} / \mathrm{g})$ \\
\hline TPC $\mu \mathrm{g}$ Catechol/g of sample & $9.27 \pm 0$ \\
TTC $\mu \mathrm{g}$ Tannic acid/g of sample & $417 \pm 0$ \\
TFC $\mu \mathrm{g}$ quercetin /g of sample & $88 \pm 0$ \\
\hline
\end{tabular}

Note: each value is expressed as mean \pm standard deviation (SD) $(n=3)$. rotation of the molecules, and also the increased mass transfer by diffusion inside the plant matrix, creating a higher driving force. ${ }^{12,37}$ These results are consistent with, ${ }^{27}$ indicating there was a $100 \%$ improvement in the yield percentage of marigold flower extract due to ultrasound treatment.

Total phenolic, flavonoids, and tannins contents The phytochemical compounds such as phenols, flavonoids, tannins in freeze-dried lantana flowers were analyzed and are reported in Table 2. The flower extracts comprised a high amount of tannins $(417 \mu \mathrm{g} / \mathrm{g})$, followed by flavonoids such as catechol $(88 \mu \mathrm{g} / \mathrm{g})$ and quercetin $(9.2 \mu \mathrm{g} / \mathrm{g})$. The total phenolic content of $8.28-52.34 \mathrm{mg} / 100 \mathrm{~g}$

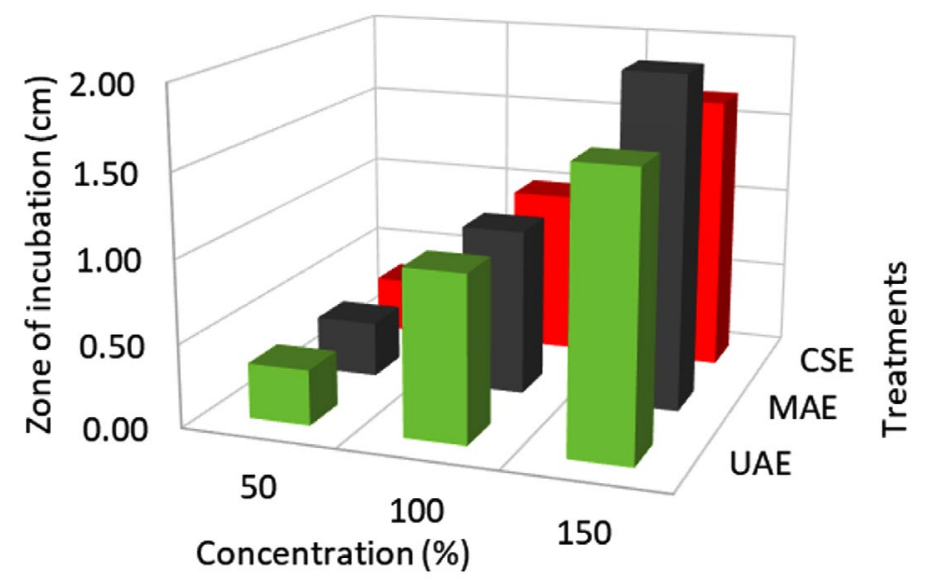

Fig. 1. Effect of extraction techniques on E.coli activity.

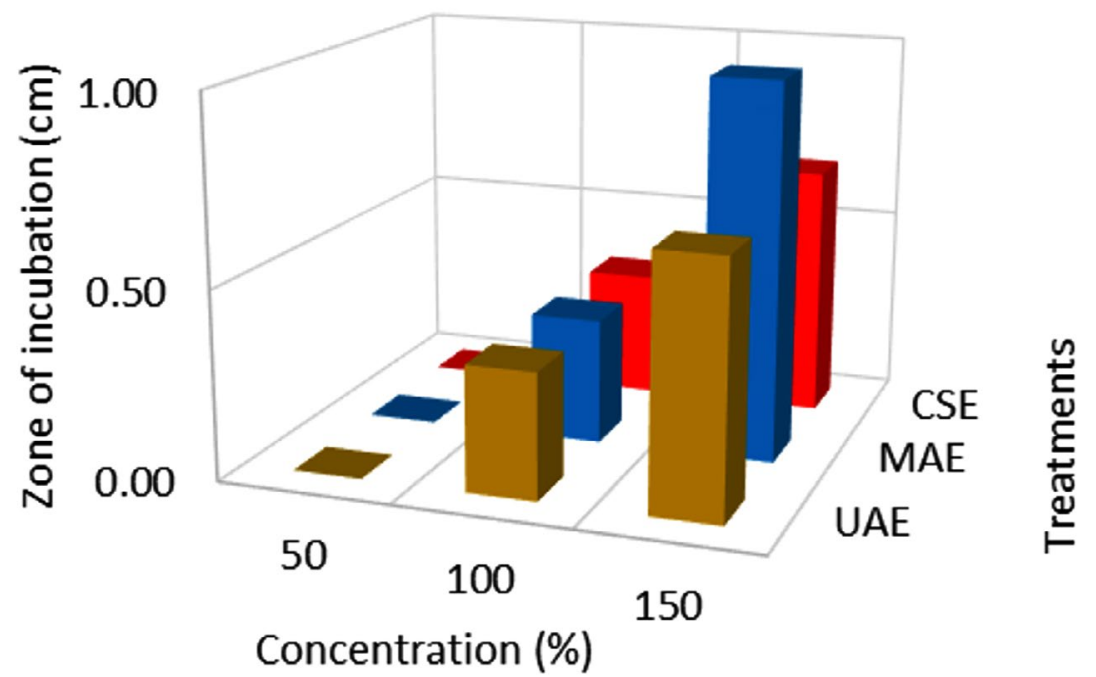

Fig. 2. Effect of extraction techniques on Salmonella activity. 
and the total flavonoid content of 1.24-7.88 $\mathrm{mg} / 100 \mathrm{~g}$ were reported for shade-dried $L$. camara flower using different extraction techniques and solvents. ${ }^{10}$ According to a study, the chloroform offered extracts containing phenolic content of $33.7 \mathrm{mg} \mathrm{GAE} / \mathrm{g}$, flavonoid content of $21.2 \mathrm{mg}$ RE/g for lantana leaf. ${ }^{6}$ The distilled water extract in the present study offered the highest polar phytocompounds like phenolics and flavonoids from lantana flowers which were due to the high polarity. Similarly, total phenolic content of 52.5 $\mathrm{mg} \mathrm{GAE} / \mathrm{g}$, total flavonoids content of $31.8 \mathrm{mg}$ $\mathrm{CAE} / \mathrm{g}$, and total tannin content of $39.4 \mathrm{mg} \mathrm{CAE} / \mathrm{g}$ were reported for lantana flower extract. ${ }^{1}$ On other hand, the total phenolic and flavonoid contents obtained in the current study were relatively much higher compared to earlier researchers. ${ }^{6,38-40}$ The difference in compounds yield could be due to the influence of environmental factors, geographical location, and the freeze-dried sample used in the present study would have retained more amount heat-sensitive bioactive compounds. ${ }^{6,41}$

Effect of solvents on antibacterial activity of flower extract

The antibacterial activity of flower extract at different concentrations was tested against three important food spoilage-causing microorganisms. The flowers extracts were prepared at three different concentrations $(50,100$, and $150 \mu \mathrm{l})$ in chloroform and distilled water solvents to test the antimicrobial potential against three organisms (E.coli, Salmonella, and S.aureus). The study results revealed that the Lantana extract was effective against all three tested bacterial species, and

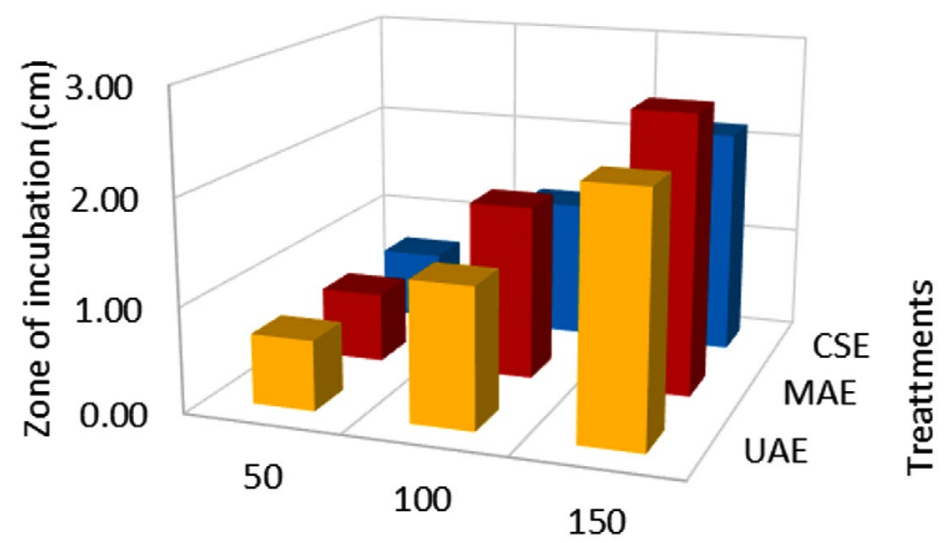

\section{Concentration (\%)}

Fig. 3. Effect of extraction techniques on S. aureus activity.

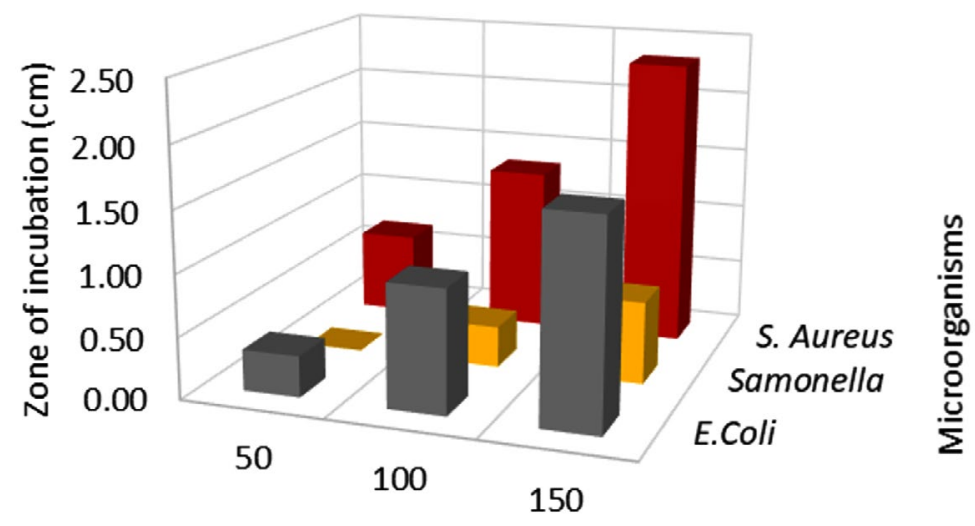

Concentration (\%)

Fig. 4. Effect of extract concentration on E.coli activity. 
the same was evident in earlier reports proving the effectiveness of lantana extract against both Gram-positive and Gram-negative bacterial strains with variable efficacy. ${ }^{1,6}$ The antibacterial activity study indicated that the chloroform-based extract did not offer any inhibitory effect, all three test microorganisms were completely resistant at all three concentrations. This was due to the poor phytochemicals release from the flowers in chloroform-based extraction. Compared to ethanol and ethyl acetate extract, the poor antibacterial activity of chloroform-based extracts against $E$. coli, $P$. aeruginosa, B. subtillis, and $S$. aureus was reported earlier. ${ }^{31}$ However, it was

Table 3. ANOVA results for Antibacterial activity of $L$. camara flower extract against different pathogens

\begin{tabular}{|c|c|c|c|c|c|}
\hline Source & Sum of Squares & $\mathrm{df}$ & Mean Square & F-value & $p$-value \\
\hline \multicolumn{6}{|c|}{ Microorganism: E. Coli } \\
\hline A-Concentration & 1.69 & 1 & 1.69 & 495.00 & $0.0001 * * * *$ \\
\hline B-Treatments & 0.007 & 2 & 0.003 & 1.15 & 0.3517 \\
\hline \multirow[t]{4}{*}{ C-Solvents } & 5.47 & 1 & 5.47 & 1605.88 & $0.0001 * * * *$ \\
\hline & & Std. Dev. & 0.0584 & $R^{2}$ & 0.9958 \\
\hline & & Mean & 0.5381 & Adjusted $\mathrm{R}^{2}$ & 0.9924 \\
\hline & & C.V. \% & 10.85 & Predicted $\mathrm{R}^{2}$ & 0.9782 \\
\hline \multicolumn{6}{|c|}{ Microorganism: Salmonella } \\
\hline A-Concentration & 0.48 & 1 & 0.48 & 89.24 & $0.0001 * * * *$ \\
\hline B-Treatments & 0.007 & 2 & 0.0036 & 0.66 & 0.5328 \\
\hline \multirow[t]{4}{*}{ C-Solvents } & 0.64 & 1 & 0.64 & 120.15 & $0.0001 * * * *$ \\
\hline & & Std. Dev. & 0.0733 & $\mathrm{R}^{2}$ & 0.9653 \\
\hline & & Mean & 0.1857 & Adjusted $\mathrm{R}^{2}$ & 0.9369 \\
\hline & & C.V. \% & 39.49 & Predicted $\mathrm{R}^{2}$ & 0.8368 \\
\hline \multicolumn{6}{|c|}{ Microorganism: S. Aerues } \\
\hline A-Concentration & 2.17 & 1 & 2.17 & 283.28 & $0.0001 * * * *$ \\
\hline B-Treatments & 0.12 & 2 & 0.064 & 8.39 & $0.0061 * *$ \\
\hline \multirow[t]{4}{*}{ C-Solvents } & 11.71 & 1 & 11.71 & 1530.51 & $0.0001 * * * *$ \\
\hline & & Std. Dev. & 0.0875 & $\mathrm{R}^{2}$ & 0.9949 \\
\hline & & Mean & 0.7905 & Adjusted $\mathrm{R}^{2}$ & 0.9908 \\
\hline & & C.V. \% & 11.07 & Predicted $\mathrm{R}^{2}$ & 0.9729 \\
\hline
\end{tabular}

${ }^{*} p<0.05$, significant; ${ }^{* *} p<0.01$, significant; ${ }^{* * *} p<0.001$, significant; $* * * * p<0.0001$, significant.

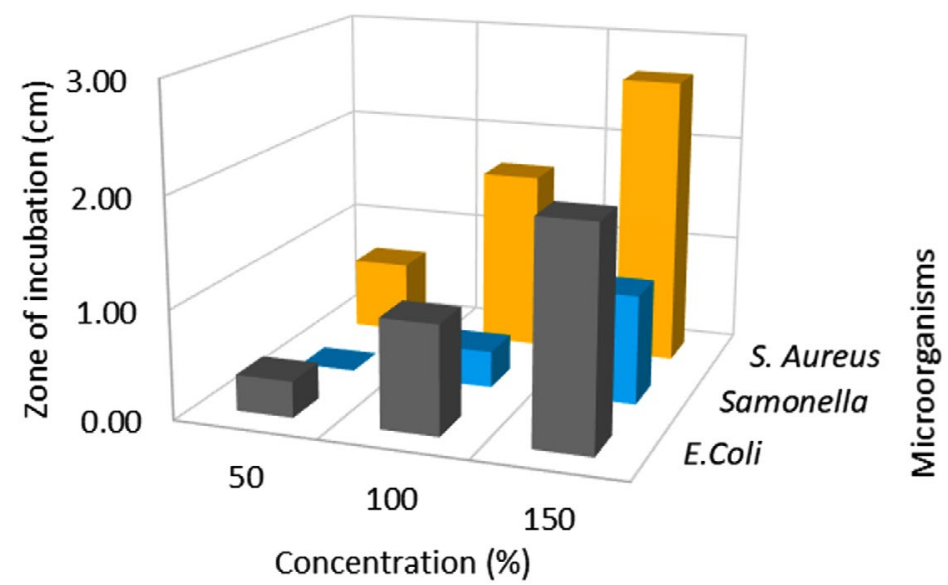

Fig. 5. Effect of extract concentration on Salmonella activity. 


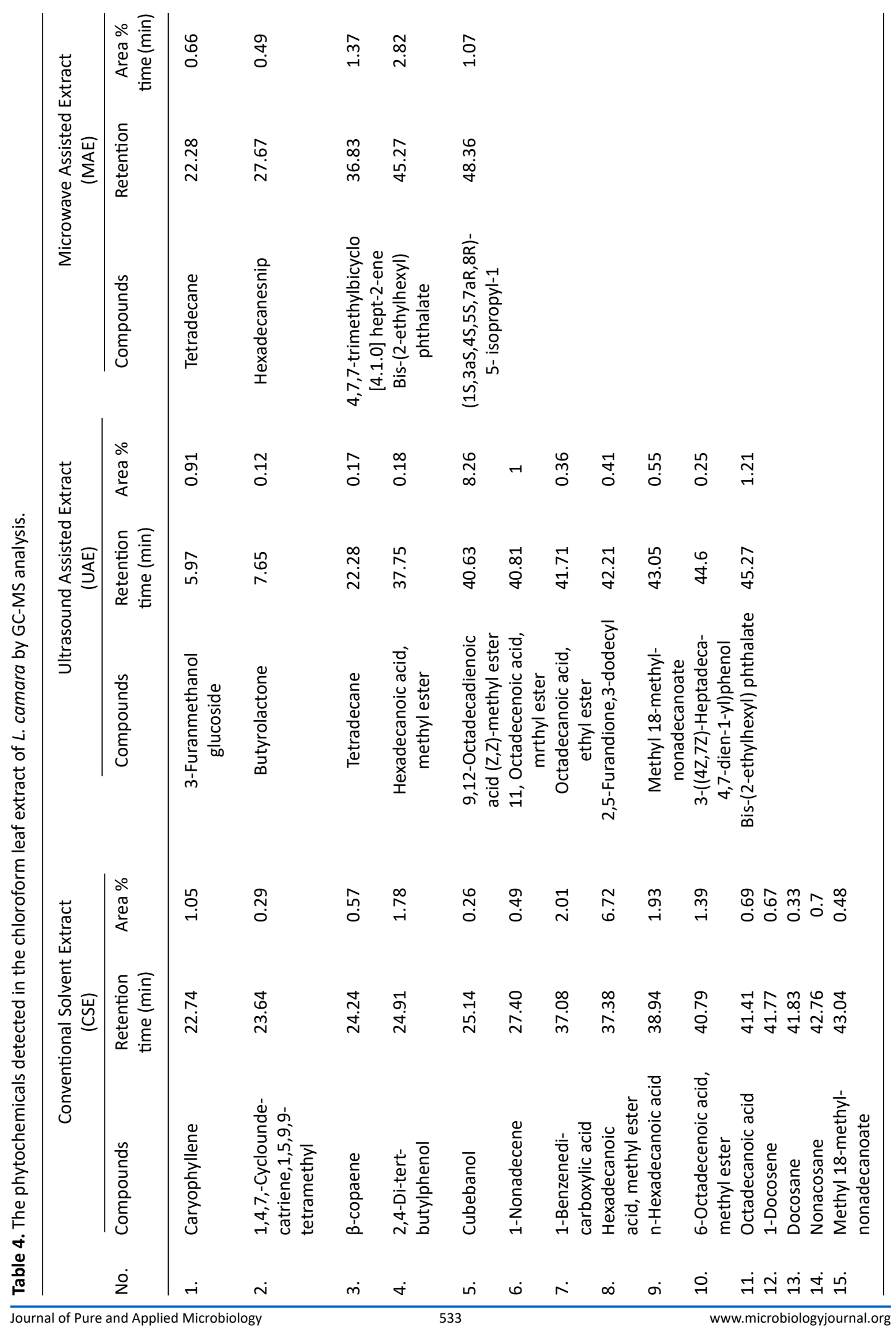




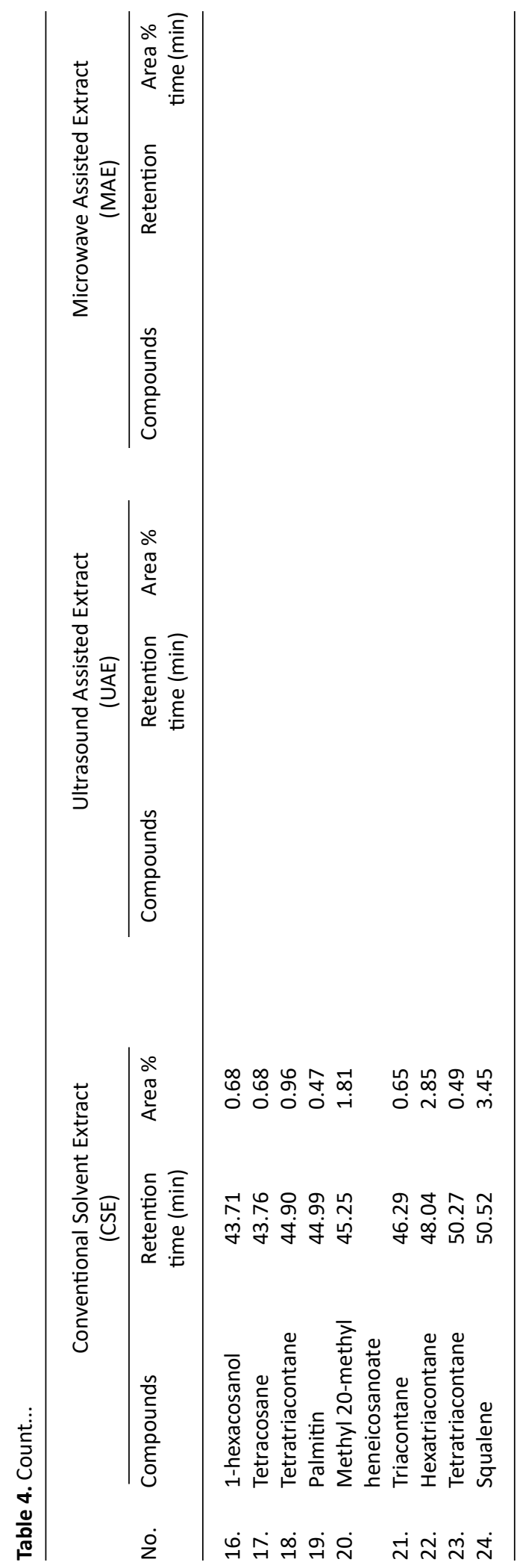

interesting to note that, distilled water-based extract offered a significant $(P<0.001)$ inhibitory effect at all three concentrations against all three test organisms (Table 3). The antibacterial properties of $L$. camara are due to the presence of Lantaadees as a biological agent. ${ }^{31}$ Another study also confirmed the presence of phenolics, anthocyanins, and proanthocyanidins in L. camara which could be responsible for the antibacterial properties of the L. camara metabolites. ${ }^{42}$ Although the mechanism of the action of these chemical constituents is not yet confirmed, it was clear that the type of solvent used significantly determines the effectiveness of the extracts. Perhaps, this is one of the main reasons behind differences in the antibacterial activities of the plants. In addition, the effectiveness of flower extract depends on the type of bacteria used for the study. ${ }^{31,43}$ Earlier reports suggest that the methanol-based microwave-ultrasound-based extract from lantana flower exhibited a significant inhibition activity against $E$. coli and S. aureus. ${ }^{10}$

Effect of extraction techniques on antibacterial activity

According to the findings, all three extraction methods (UAE, MAE, and CSE) using distilled water as a solvent exhibited similar zone of inhibition values ranging from 0.3 to $2.6 \mathrm{~cm}$ against E.coli, Salmonella, and $S$. aureus (Fig. 1, 2 \& 3). The extraction techniques had a significant $(P<0.001)$ effect against the growth of E.coli and S. aureus, but there was no significant inhibition activity against Salmonella (Table 3). The significant inhibitory activity of Lantana extract against $E$. coli and $S$. aureus was also reported. ${ }^{10}$ The microwave-assisted extract exhibited a strong antibacterial activity $(2.0-2.67 \mathrm{~mm})$ and followed by ultrasound-assisted extract $(1.67-2.67 \mathrm{~mm}$ ) and solvent extracted (1.67-2.17 $\mathrm{mm}$ ) against E.coli, Salmonella, and S. aureus (Fig. 1, 2 \& 3). The greater in-vitro antimicrobial activities due to high polyphenols contents in the MAE technique were also reported by Quintero. ${ }^{12}$ Consequently, the antimicrobial activity was high for the extracts obtained by UAE and MAE, this was due to the greater amount of phytochemicals in comparison to conventional solvent extraction technique. The results of higher antimicrobial activity by UAE and MAE compared to conventional leaching were also reported by other authors. ${ }^{12,44,45}$ The antibacterial 
activity results obtained for ultrasound-microwave assisted distilled water extracts differs from the results reported earlier, ${ }^{31}$ this was due to variation in the type of solvents used in these studies. However, the antibacterial zone of inhibition for ethyl acetate-based extracts ranged from 1-2.1 and $0.9-1.5 \mathrm{~cm}$, respectively which are comparable with present findings and reports by some authors. $^{12,13,45,46}$

\section{Effect of extract concentration on antibacterial activity}

In this assay, L. camara extracts antibacterial potential has been studied broadly using three different concentrations viz, 50, $100 \& 150 \mu \mathrm{l}$ against three common foodborne pathogens. Among all the concentrations, $150 \mu \mathrm{l}$ flower extract (MAE) had significant ( $p<0.001$ ) inhibitory effect against E.coli, Salmonella, and $S$. aureus (Fig. 4,5 \& 6; Table 3). MAE technique had a superior inhibitory effect against all the pathogens. The antibacterial activity increased with an increase in the concentration irrespective of the extraction techniques. The earlier reports suggested that the antibacterial activity gets enhanced with an increase in concentration irrespective of the solvents. ${ }^{6}$ At $150 \mu$ l concentration E.coli $(2.00 \mathrm{~cm})$ recorded the lowest growth, followed by $S$. aureus $(2.67 \mathrm{~cm})$ and the least growth was observed in Salmonella $(1.0 \mathrm{~cm})$. Significant growth inhibition was observed as concentration increased from

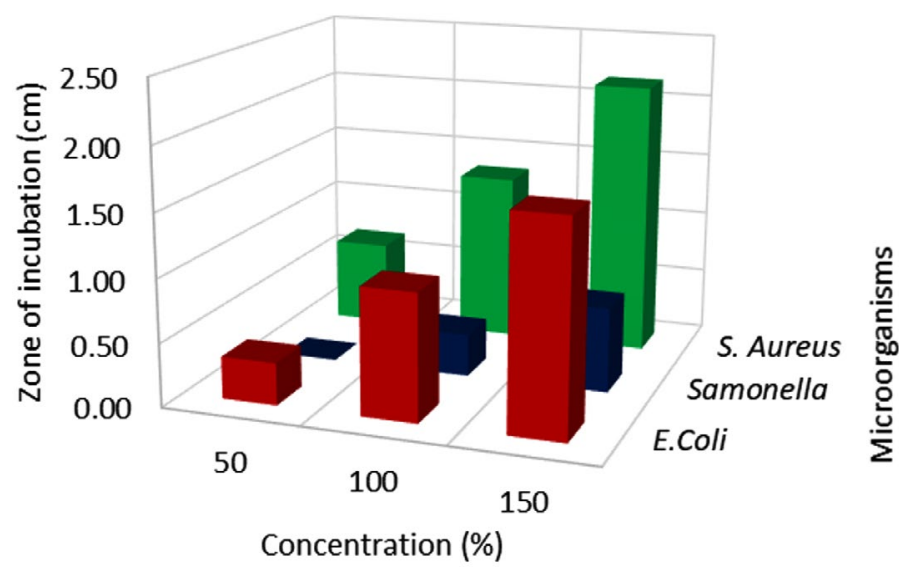

Fig. 6. Effect of extract concentration on S. aureus activity.

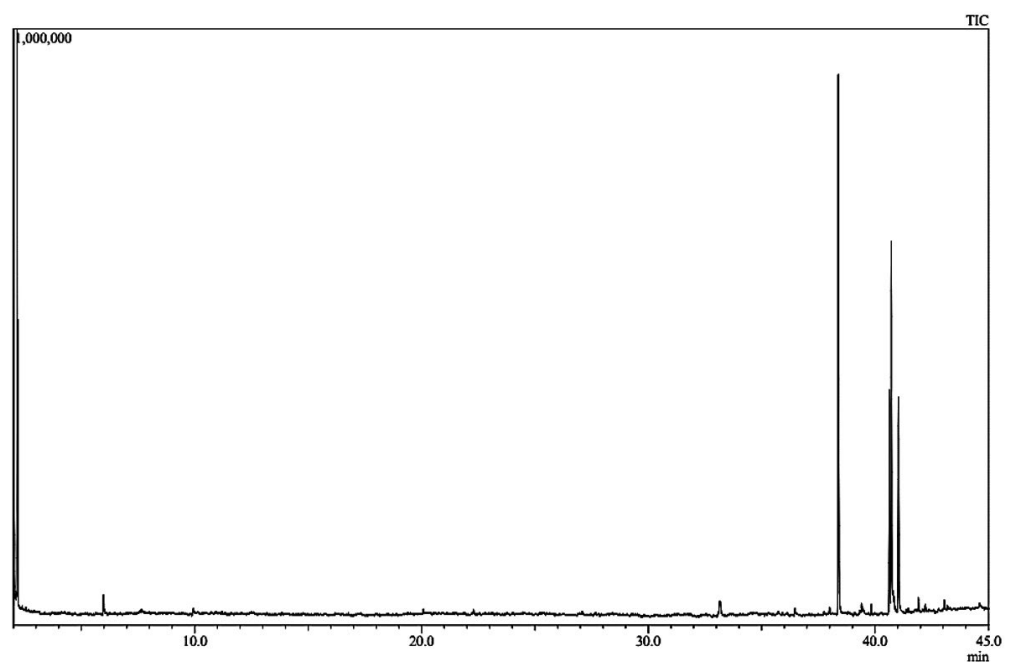

Fig. 7. GC-MS chromatography of L. camara flower extract by UAE. 


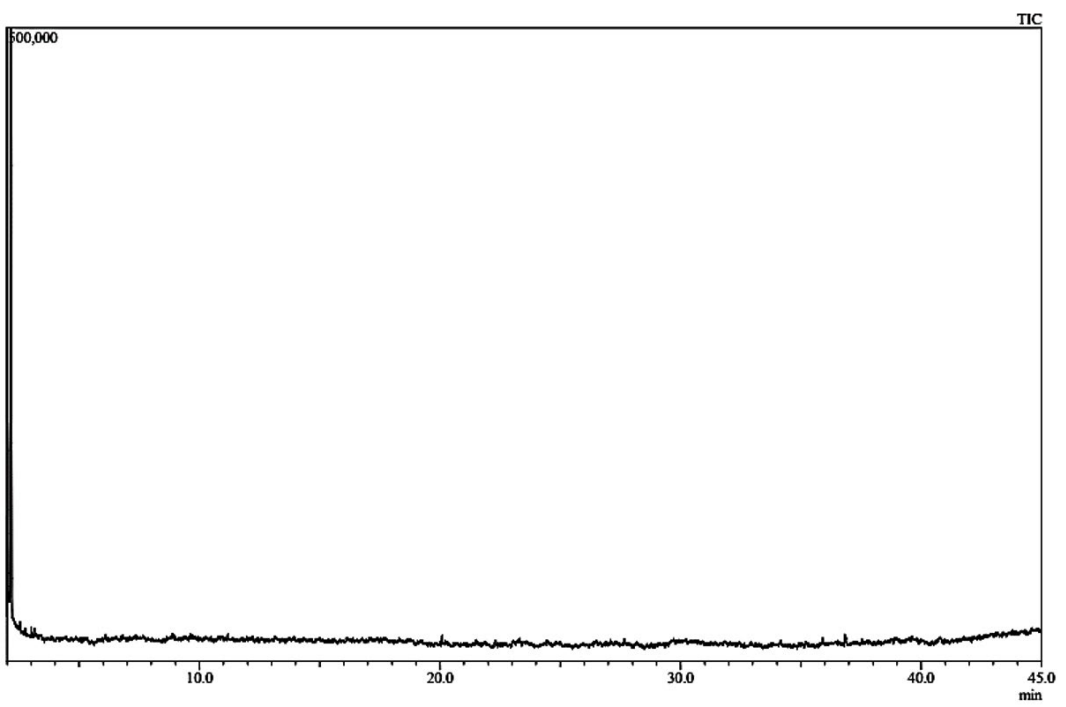

Fig. 8. GC-MS chromatography of L. camara flower extract by MAE.

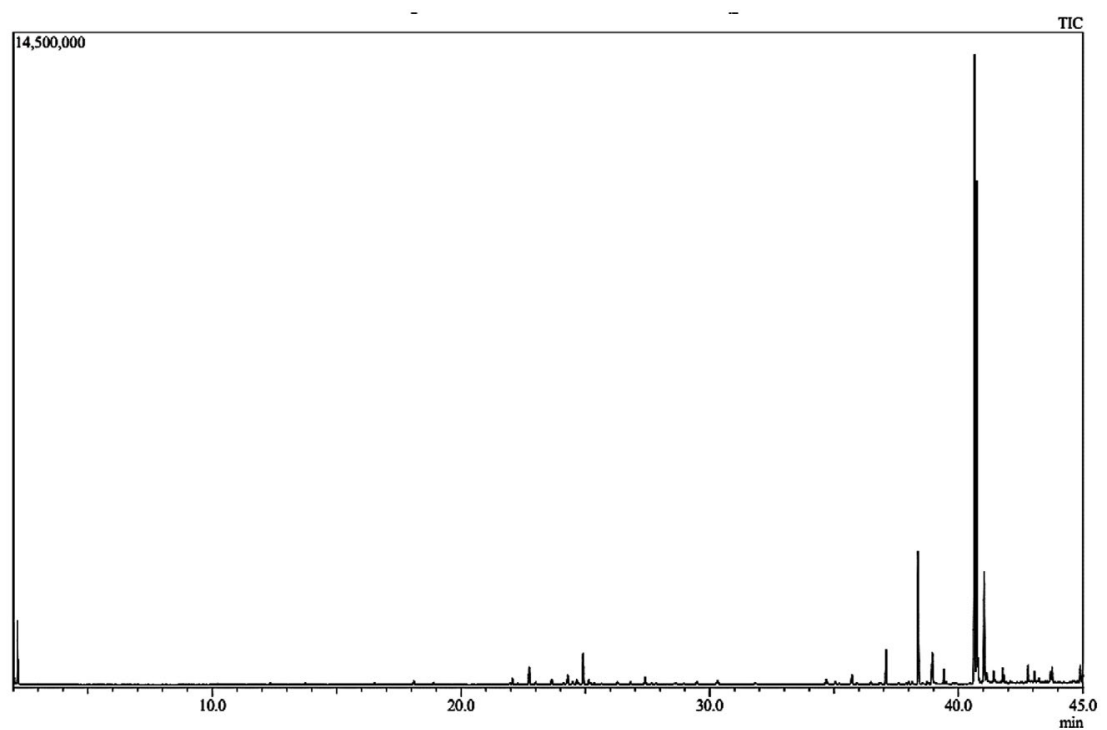

Fig. 9. GC-MS chromatography of L. camara flower extract by CSE

50 to $150 \mu \mathrm{l}$, against all the pathogens. There was no significant growth inhibition observed at 50 $\mu$ concentration $(0,0.33,0.67 \mathrm{~cm})$ with respect to different extraction techniques (Fig. 4, 5 \& 6). Similar antibacterial properties of $L$. camara have been reported by other researchers. ${ }^{31,47}$ In conclusion, the study of $L$. camara has displayed antimicrobial activities due to the differences in the biochemical and phytochemical compositions of the plant materials used. In addition, irrespective of concentrations all the extracts showed poor to significant antibacterial activities which were due to the presence of lantadenes and theveside in the lantana extracts. ${ }^{31,42}$

\section{GC-MS analysis}

The GC-MS profiling of bioactive compounds in different extraction methods (UAE, MAE, and CS) of flower extract revealed the 
identification of phytochemical compounds (Fig. 7,8 \& 9). Among several identified phytochemicals, hexadecanoic acid was the major compound found in all three extraction methods (Table 4). The aqueous extract exhibited an inhibitory effect on E.coli, Salmonella, and S. aureus. The antibacterial effect of the aqueous extract is due to the presence of phytoconstituents such as terpenes, flavonoids, glycosides, and steroids. The chloroform extract failed to exhibit an antibacterial effect due to the absence of alkaloids, saponins, and anthraquinones which may be due to its neutralizing effect which is in line with previous studies. ${ }^{6}$ The active constituents present in the aqueous extract of $L$. camara are speculated to disrupt the membrane integrity by enhancing the permeability of antimicrobial agents inside the cell and inhibit their growth. ${ }^{5}$ It was interesting to note that (Table 4), the highest (24) polyphenol compounds were identified in the CSE sample, followed by the UAE sample (11) and MAE sample (5). The polyphenol compounds are sensitive to heat, pressure, and extraction process. The degradation of polyphenols in the UAE was associated with generation of cavitation of the bubbles and micro domains which resulted in a greater temperature ramp and rapid pressure change. Whereas, in MAE it was because of the rapid heating in the whole system due to change in ionic mobility and molecular rotation which results in denaturation of bioactive compounds. ${ }^{12,13}$

\section{CONCLUSION}

L. camara flower essential oil is known to have a remarkable variation in its phenolic compositions based on the geographical location of the plant, drying methods, solvents used, and extraction techniques. Based on the results, it could be concluded that the use of ultrasound and microwave treatment improves the flower extract yields and antimicrobial properties of flower extract. The distilled water extracts showed significant antimicrobial activity against E.coli, Salmonella, and S. aureus organisms. The chloroform-based extraction techniques failed to extract bioactive compounds due to the nonpolarity of solvent, which also resulted in a poor zone of inhibitions against all the organisms. The GC-MS study revealed that the freeze-dried flower extract consisted of phytochemicals such as terpenes, flavonoids, glycosides, and steroids. The study results indicated that the solvent, ultrasound-microwave treatments affect the extract yield, polyphenols compounds, and antibacterial activity. Therefore, should be carefully selected to achieve the desired extraction objectives. The Lantana flower extract has a great potential to inhibit the most common food spoilage pathogens, which can be utilized as a potential source for the development of natural preservatives to prevent the spoilage of dairy food products.

\section{ACKNOWLEDGMENTS}

The authors are thankful to Ms. Vishaka for her assistance to carry out the experiments, Mr. Vijay Kumar for GC-MS analysis \& characterization, Ms. Nafiya, Ms. Preeja, and Mr. Sambu for their assistance in sample procurement and extraction trials. The Department of Food Technology, Ramaiah University of Applied Sciences, India facilitated the work is also acknowledged.

\section{CONFLICT OF INTEREST}

The authors declare that there is no conflict of interest.

\section{AUTHORS' CONTRIBUTION}

All authors have made a substantial, direct, and intellectual contribution to the work, and approved it for publication.

\section{FUNDING}

This work was supported by Ramaiah University of Applied Sciences, India SEED Grant Ref. No. 02/FT/FLAHS/RUAS/2021

\section{DATA AVAILABILITY}

All the data sets generated and analyzed during this study are included in the manuscript.

\section{ETHICS STATEMENT}

Not applicable.

\section{REFERENCES}

1. Venkatappa AH, Amrutanand T, Majumdar SP, Harish M. Application of Lantana camara Flower Extract as a Natural Coloring Agent with Preservative Action. Asian Journal of Biological Sciences. 2020;13(4):361-369. doi: 10.3923/ajbs.2020.361.369

2. Khan M, Mahmood A, Alkhathlan HZ. Characterization 
of leaves and flowers volatile constituents of Lantana camara growing in central region of Saudi Arabia. Arab J Chem. 2016;9(6):764-774. doi: 10.1016/j. arabjc.2015.11.005

3. Ghisalberti EL. Lantana camara L. (Verbenaceae) Fitoterapia. 2000;71(5):467-486. doi: 10.1016/S0367326x(00)00202-1

4. Sharma OP, Sharma S, Pattabhi V, Mahato SB, Sharma PD. A review of the hepatotoxic plant Lantana camara. Crit Rev Toxicol. 2007;37(4):313-352. doi: 10.1080/10408440601177863

5. Saraf A, Quereshi S, Sharma K, Khan NA. Antimicrobial activity of Lantana camara L. J Exp Sci. 2011;2(10):5054.

6. Swamy MK, Sinniah UR, Akhtar MS. In vitro pharmacological activities and GC-ms analysis of different solvent extracts of Lantana camara leaves collected from tropical region of Malaysia. Evidencebased Complement Altern Med. 2015;2015:506413. doi: $10.1155 / 2015 / 506413$

7. Anand SP, Sati N. Artificial Preservatives and Their Harmful Effects: Looking Toward Nature for Safer Alternatives. Int J Pharm Sci Res. 2013;4(7):2496-2501. doi: 10.13040/IJPSR.0975-8232.4(7).2496-2501

8. Kusuma H, Rohadi TI, Daniswara EF, Altway A, Mahfud M. Preliminary study: Comparison of kinetic models of oil extraction from vetiver (vetiveria zizanioides) by microwave hydrodistillation. Korean Chem Eng Res. 2017;55(4):574-577. doi: 10.9713/kcer.2017.55.4.574

9. Kusuma H, Mahfud M. Microwave-assisted hydrodistillation for extraction of essential oil from patchouli (Pogostemon cablin) leaves. Period Polytech Chem Eng. 2017;61(2):82-92. doi: 10.3311/PPch.8676

10. Manzoor M, Anwar F, Sultana B, Mushtaq M. Variation in antioxidant and antimicrobial activities in Lantana camara L. flowers in relation to extraction methods. Acta Sci Pol Technol Aliment. 2013;12(3):283-294.

11. Chemat F, Rombaut N, Sicaire AG, Meullemiestre A, Fabiano-Tixier AS, Abert-Vian M. Ultrasound assisted extraction of food and natural products. Mechanisms, techniques, combinations, protocols and applications. A review. Ultrason Sonochem. 2017;34:540-560. doi: 10.1016/j.ultsonch.2016.06.035

12. Quiroz JQ, Torres AC, Ramirez LM, Garcia MS, Gomez GC, Rojas J. Optimization of the microwaveassisted extraction process of bioactive compounds from annatto seeds (Bixa orellana L.). Antioxidants. 2019;8(2):37. doi: 10.3390/antiox8020037

13. Quintero Quiroz J, Naranjo Duran AM, Silva Garcia M, Ciro Gomez GL, Rojas Camargo JJ. Ultrasound-assisted extraction of bioactive compounds from annatto seeds, evaluation of their antimicrobial and antioxidant activity, and identification of main compounds by LC/ ESI-MS analysis. Int J Food Sci. 2019;2019:3721828. doi: $10.1155 / 2019 / 3721828$

14. Da Rocha CB, Noreña CPZ. Microwave-Assisted Extraction and Ultrasound-Assisted Extraction of Bioactive Compounds from Grape Pomace. Int J Food Eng. 2020;16(1-2). doi: 10.1515/ijfe-2019-0191

15. Kusuma HS, Mahfud M. Comparison of kinetic models of oil extraction from sandalwood by microwave-assisted hydrodistillation. Int Food Res J.
2017;24(4):1697-1702.

16. Mahfud M, Putri DKY, Dewi IEP, Kusuma HS. Extraction of essential oil from cananga (Cananga odorata) using solvent-free microwave extraction: A preliminary study. Rasayan J Chem. 2017;10(1):86-91. doi: 10.7324/RJC.2017.1011562

17. Kusuma H, Putri D, Dewi I, Mahfud M. Solventfree microwave extraction as the useful tool for extraction of edible essential oils. Chem Chem Technol. 2016;10(2):213-218. doi: 10.23939/chcht10.02.213

18. Kusuma HP, Putri DKY, Dewi IEP, Mahfud M. Solventfree microwave extraction of essential oil from dried basil (Ocimum basilicum L.) leaves. Chem Chem Technol. 2018;12(4):543-548. doi: 10.23939/ chcht12.04.543

19. Azwanida NN. A Review on the Extraction Methods Use in Medicinal Plants, Principle, Strength and Limitation. Med Aromat Plants. 2015;04(03): 1000196. doi: 10.4172/2167-0412.1000196

20. Kusuma HS, Mahfud M. Kinetic studies on extraction of essential oil from sandalwood (Santalum album) by microwave air-hydrodistillation method. Alexandria Eng J. 2018;57(2):1163-1172. doi: $10.1016 / j$. aej.2017.02.007

21. Chávez GJG, Villa JA, Ayala-Zavala JF, et al. Technologies for Extraction and Production of Bioactive Compounds to be Used as Nutraceuticals and Food Ingredients: An Overview. Compr Rev Food Sci Food Saf. 2013;12(1):523. doi: 10.1111/1541-4337.12005

22. Basu S, Ghosh A, Hazra B. Evaluation of the antibacterial activity of Ventilago madraspatana Gaertn., Rubia cordifolia Linn., and Lantana camara Linn.: Isolation of emodin and physcion as active antibacterial agents. Phyther Res. 2005;19(10):888-894. doi: 10.1002/ ptr.1752

23. Dabur R, Gupta A, Mandal TK, et al. Antimicrobial activity of some medicinal plants. African J Tradit Complement Altern Med. 2007;4(3):313-318. doi: 10.4314/ajtcam.v4i3.31225

24. Parekh J, Chanda SV. In vitro antimicrobial activity and phytochemical analysis of some Indian medicinal plants. Turkish J Biol. 2007;31(1):53-58.

25. Salar RK, Dhall A. Antimicrobial and free radical scavenging activity of extracts of some indian medicinal plants. J Med Plants Res. 2010;4(22):23132320.

26. Truong DH, Nguyen DH, Ta NTA, Bui AV, Do TH, Nguyen HC. Evaluation of the use of different solvents for phytochemical constituents, antioxidants, and in vitro anti-inflammatory activities of severinia buxifolia. J Food Qual. 2019;2019:8178294. doi: $10.1155 / 2019 / 8178294$

27. Sivakumar V, Vijaeeswarri J, Anna JL. Effective natural dye extraction from different plant materials using ultrasound. Ind Crops Prod. 2011;33(1):116-122. doi: 10.1016/j.indcrop.2010.09.007

28. Martinez-Ramos T, Benedito-Fort J, Watson NJ, RuizLopez II, Che-Galicia G, Corona-Jimenez E. Effect of solvent composition and its interaction with ultrasonic energy on the ultrasound-assisted extraction of phenolic compounds from Mango peels (Mangifera indica L.). Food Bioprod Process. 2020;122:41-54. doi: 
10.1016/j.fbp.2020.03.011

29. Verma SC, Jain CL, Kumari A, Padhi MM, Devalla RB. Microwave-assisted extraction and rapid isolation of ursolic acid from the leaves of Eucalyptus $\times$ hybrida Maiden and its quantification using HPLC-diode array technique. J Sep Sci. 2013;36(7):1255-1262. doi: 10.1002/jssc.201200950

30. Sulaiman M, Abd Manan F. Analysis of total phenolics, tannins and flavonoids from Moringa oleifera seed extract. J Chem Pharm Res. 2015;7:132-135.

31. Ganjewala D, Sam S, Khan KH. Biochemical compositions and antibacterial activities of Lantana camara plants with yellow, lavender, red and white flowers. Eur Asian J Biosci. 2009;3:69-77. doi: 10.5053/ ejobios.2009.3.0.10

32. De S, Dey A, Sudhakar Babu AMS, Aneela S. Phytochemical and GC-MS analysis of bioactive compounds of Sphaeranthus amaranthoides Burm. Pharmacogn J. 2013;5(6):265-268. doi: 10.1016/j. phcgj.2013.09.005

33. Jothi D. Extraction of natural dyes from African marigold flower (Tagetes ereectal) for textile coloration. Autex Res J. 2008;8(2):49-53.

34. Sultana B, Anwar F, Ashraf M. Effect of extraction solvent/ technique on the antioxidant activity of selected medicinal plant extracts. Molecules. 2009;14(6):21672180. doi: $10.3390 /$ molecules 14062167

35. Xu DP, Zheng J, Zhou Y, Li Y, Li S, Li H-B. Ultrasoundassisted extraction of natural antioxidants from the flower of Limonium sinuatum: Optimization and comparison with conventional methods. Food Chem. 2017;217:552-559. doi: 10.1016/j. foodchem.2016.09.013

36. Sumere BR, de Souza MC, dos Santos MP, et al. Combining pressurized liquids with ultrasound to improve the extraction of phenolic compounds from pomegranate peel (Punica granatum L.). Ultrason Sonochem. 2018;48:151-162. doi: 10.1016/j. ultsonch.2018.05.028

37. Alupului A, Calinescu I, Lavric V. Microwave Extraction of active principles from medicinal plants. UPB Sci Bull Ser B Chem Mater Sci. 2012;74(2):129-142.

38. Naz R, Bano A. Phytochemical screening, antioxidants and antimicrobial potential of Lantana camara in different solvents. Asian Pacific J Trop Dis. 2013;3(6):480-486. doi: $10.1016 /$ S22221808(13)60104-8

39. Anwar F, Shaheen N, Shabir G, Ashraf M, Alkharfy KM, Gilani $\mathrm{AH}$. Variation in antioxidant activity and phenolic and flavonoid contents in the flowers and leaves of Ghaneri (Lantana camara L.) as affected by different extraction solven. Int J Pharmacol. 2013;9(7):442-453. doi: 10.3923/ijp.2013.442.453

40. Kumar S, Sandhir R, Ojha S. Evaluation of antioxidant activity and total phenol in different varieties of Lantana camara leaves. BMC Res Notes. 2014;7:560. doi: 10.1186/1756-0500-7-560

41. Kidon M, Grabowska J. Bioactive compounds, antioxidant activity, and sensory qualities of redfleshed apples dried by different methods. LWT. 2021;136:110302. doi: 10.1016/j.Iwt.2020.110302

42. Bhakta D, Ganjewala D. Effect of Leaf Positions on Total Phenolics, Flavonoids and Proanthocyanidins Content and Antioxidant Activities in Lantana Camara (L). J Sci Res. 2009;1(2):363-369. doi: 10.3329/jsr.v1i2.1873

43. Pratihast K, Kumar R, Bharti SK. Comparative antimicrobial activity of ethanolic and aqueous extract of Tinospora cordifolia. The Pharma Innovation Journal. 2019;8(3):129-136.

44. Zhang LL, Xu M, Wang YM, Wu DM, Chen JH. Optimizing ultrasonic ellagic acid extraction conditions from infructescence of platycarya strobilacea using response surface methodology. Molecules. 2010;15(11):79237932. doi: 10.3390/molecules 15117923

45. Yolmeh M, Habibi-Najafi MB, Shakouri S, Hosseini F. Comparing Antibacterial and Antioxidant Activity of Annatto Dye Extracted by Conventional and Ultrasound-Assisted Methods. Zahedan J Res Med Sci. 2015;17(7). doi: 10.17795/zjrms1020

46. Vasu S, Palaniyappan V, Kothandam HP, Badami S. Microwave facilitated extraction of Bixin from Bixa orellana and it's in-vitro antioxidant activity. Der Pharm Lett. 2010;2(2):479-485.

47. Deena MJ, Thoppil JE. Antimicrobial activity of the essential oil of Lantana camara. Fitoterapia. $2000 ; 71(4): 453-455$. doi: $10.1016 / 50367$ $326 \times(00) 00140-4$ 